\title{
STABILITY AND REGENERABILITY OF CATALYSTS FOR THE DESTRUCTION OF TARS FROM BIOMASS AND BLACK LIQUOR GASIFICATION
}

Final Report For The Period

February 7, 2000-February 6, 2003

Dr. Pradeep K. Agrawal (PI)

School of Chemical \& Biomolecular Engineering

Georgia Institute of Technology

Atlanta, Georgia 30332-0100

Prepared for The UNITED STATED DEPARTMENT OF ENERGY UNDER CONTRACT NUMBER DE-FC07-00ID13875 


\begin{abstract}
The goal of this project was to develop catalytic materials and processes that would be effective in the destruction of tars formed during the gasification of black liquor and biomass. We report here the significant results obtained at the conclusion of this two year project. A one year no-cost extension of this project was requested and approved.
\end{abstract}

Task 1. Was completed. We identified Group VIII transition metal catalysts as active for the gasification of benzene (model tar compound) using steam. These catalysts, however, don't have any sulfur tolerance. We have identified Group VI B sulfide materials such as tungsten sulfide or CobaltMolybdenum sulfides as active catalysts for the reaction, and with good tolerance towards sulfur.

Task 2. ThermoChem. Inc. and Kellogg Brown Root were identified as potential partners for the industrial site pilot reactor studies. However, no pilot scale work could be done because their gasification reactors didn't come on stream which was a necessary step before we could go and perform the pilot scale reactor testing of the chosen catalysts. However, all the pieces and designs were completed to carry out such studies.

Task 3. Was completed. It involved characterization of aged catalysts. X-ray diffraction studies showed that Group VIII transition metal catalysts lost their activity in the presence of sulfur, due to the formation of sulfide and sulfate phases. Also complex phase transformations were observed in the presence of alkali compounds.

Task 4. Was completed. The goal was to develop effective regeneration methods. It was found that sulfur-poisoned Group VIII transition metal catalysts could not be regenerated using oxidation or steam treatments at elevated temperatures. Our efforts focused instead on the regeneration of carbondeactivated catalysts. The efforts to regenerate Co-Mo catalysts using oxidation treatment were successful in removing carbon. The resulting material was subsequently sulfided. It was possible to achieve original catalytic activity even after three weeks of aging.

With the exception of pilot scale testing of the chosen catalysts, all other objectives for the project were completed. 


\section{BACKGROUND}

Biomass and black liquor gasification, because of their higher energy efficiency and lower capital costs, have the promise to be attractive alternatives for traditional combustion processes. One of the major challenges facing the commercialization of integrated combined cycle gasification technology is the formation of tars. The formation of tars (semi-volatile and non-volatile organic matter) represents a potential loss of fuel and a contaminant that must be removed from the product gas before it is fired into a gas turbine. In black liquor gasification, tars are an unacceptable contaminant in green liquor with a potential safety hazard. Tars are formed in all gasification processes but they are a greater problem in biomass and black liquor gasification than in fossil fuel gasification. The amount and composition of the tar compounds depend greatly on the temperature and composition during the gasification process. In an earlier study $(1,2)$, tars formed during gasification of kraft liquor consisted of mono-aromatic and poly-aromatic compounds. Benzene, toluene, and xylene were the primary tar species, but naphthalene, phenanthrene, acenaphthalene, chrysene, and perylene were also observed.

Methods to eliminate tars include thermal cracking, steam reforming, and catalytic destruction. Of these, catalytic approach is the most promising alternative to destroy tar compounds since it can convert tar to gaseous fuels at moderate temperatures. Several different catalytic materials have been tested for biomass tar destruction, including dolomite, nickel and cobalt based catalysts (3-8). The rapid deactivation of catalysts in the fuel gas presents a major challenge. Catalytic destruction of tars involves breaking as well as the formation of carbon-carbon, carbon-oxygen, and carbon-hydrogen bonds. Since similar bond transformations are observed in petroleum processing (for example hydrotreating, catalytic reforming etc.), Group VIII transition metals would appear to be prime catalytic materials for tar destruction (9). Catalytic deactivation due to carbon and sulfur may be expected in both processes $(10,11)$. However, there are two other potential sources of catalyst deactivation not encountered in the petroleum processing industry. The first is the presence of chlorine as $\mathrm{HCl}$ in the reaction enviroment (up to $1000 \mathrm{ppm}$ ). Secondly, high temperature operations (above $700{ }^{\circ} \mathrm{C}$ ) may lead alkali metal (Na) to diffuse into the bulk of the catalytic metal, thus causing the catalytic phase to loose its structural strength.

The objectives of our study were to investigate various catalytic materials for tar destruction. The goal was to develop stable catalysts as well as to define approaches for regeneration of deactivated catalysts. We report below the results obtained from our sulfur poisoning studies as well as the potential of using sulfide phases as active catalysts for steam reforming of tars.

In order to destroy these tar compounds, catalytic conversion appears to be the most promising alternative since it can convert tars to fuel gas at moderate temperatures. A great deal of research has been conducted in search for superior catalysts and the optimal conditions for tar destruction processes. Extensive research has been performed with a variety of catalysts, both metallic and non-metallic. Mixing catalysts with the biomass (in-situ) gives unfavorable results for several reasons: coke formation because biomass is 
in contact with the catalysts, breaking of catalyst particles, and agglomeration of catalysts and biomass particles. Use of a secondary reactor to destroy tar compounds is a more feasible approach. The catalyst deactivation by sulfur is a major consideration in the development of a successful catalytic process. During black liquor gasification, high levels of $\mathrm{H}_{2} \mathrm{~S}$ are expected to be present in the product gas stream along with other sulfurcontaining species such as $\mathrm{COS}, \mathrm{CS}_{2}, \mathrm{SO}_{2}$, and mercaptans. A large amount of sodium, chlorine, and potassium salts in the form of fine particles in the gas stream typically found in black liquor gasification would also affect the catalyst performance. The catalysts deactivate rapidly due to the poisoning by sulfur-, chlorine, and/or carbonaceous species in the feedstock. The amounts of alkali metals and sulfur obtained from black liquor gasification are different than those obtained from the biomass gasification, especially as it concerns the catalytic gasification of tar compounds. However, the pathways for the tar gasification as well as catalyst deactivation would be similar in these two processes. Use of guard beds can prolong the catalysts life against sulfur, but it is of little help in deactivation by carbonaceous species.

\section{APPROACH}

The protocols for increased catalyst life involve defining processing conditions and catalytic materials such that there are minimal transformations of the catalytically active solid-state process. In terms of processing conditions, the main variable is reducing vs. oxidizing environment at the catalyst surface, which can be altered by choosing between $\mathrm{H}_{2}$, steam, and/or air. It should be kept in mind, however, that steam is a natural choice, since it is present in the fuel gas obtained from black liquor gasification. Use of air or oxygen to oxidize tar compounds may lead to lowered energy efficiency. The formation of stable catalytic phase might involve the use of spinels (e.g. nickel aluminate) copper chromite, nickel-chromite, or sulfided metals (e.g. CoS- $\mathrm{MoS}_{2} / \mathrm{Al}_{2} \mathrm{O}_{3}$ ), which have demonstrated gasification activity and should be resistant to poisoning by sulfur. This research aims to focus on both classes of materials. The work to be accomplished has been divided into several tasks:

\section{Task 1. Bench Scale Reactor Studies}

This was the focus of our efforts during the first year. A variety of catalysts were examined for their activity and sulfur tolerance. Also, the effect of alkali compounds was examined. These studies were conducted using benzene as a model tar compound in a laboratory scale reactor operating in a fixed bed mode at atmospheric pressure.

\section{Task 2. Industrial Site Reactor Studies}

These studies were to be conducted using an industrial feed stream (at the site of the industry partner) with catalyst candidate(s) chosen based on the results from Task 1 . We identified two industrial partners and visited one of the sites. We had designed the pilot scale reactor as well as had assembled the necessary components for the same. However, we never were able to do these runs because the gasification units didn't come on stream 
as expected. There was no other feasible site within the US to conduct these tests during the period of this project.

\section{Task 3. Aged Catalyst Characterization}

Selected aged catalysts from bench scale reactor studies were characterized using x-ray diffraction (XRD) and scanning electron microscopy (SEM), and energy-dispersion analysis (EDAX). The purpose was to understand the underlying deactivation phenomena and to develop effective catalyst regeneration schemes.

\section{Task 4. Catalyst Regeneration Studies}

Task 4 involved regeneration of catalysts deactivated either by sulfur or carbon. The catalyst regeneration scheme(s) were developed based on the results from Task 3, and were tested in the bench scale reactor.

\section{EXPERIMENTAL APPARATUS \& METHODS}

Figure 1 shows a simplified schematic diagram of the catalytic reactor system used for bench scale studies. The reactor was fabricated from alumina tubing (1/2" in diameter x $1 \mathrm{ft}$ long). The catalyst was supported on a fritted disc located in the middle of the alumina tube. All the gas lines were heat-traced to prevent condensation of the reactant or any product species.

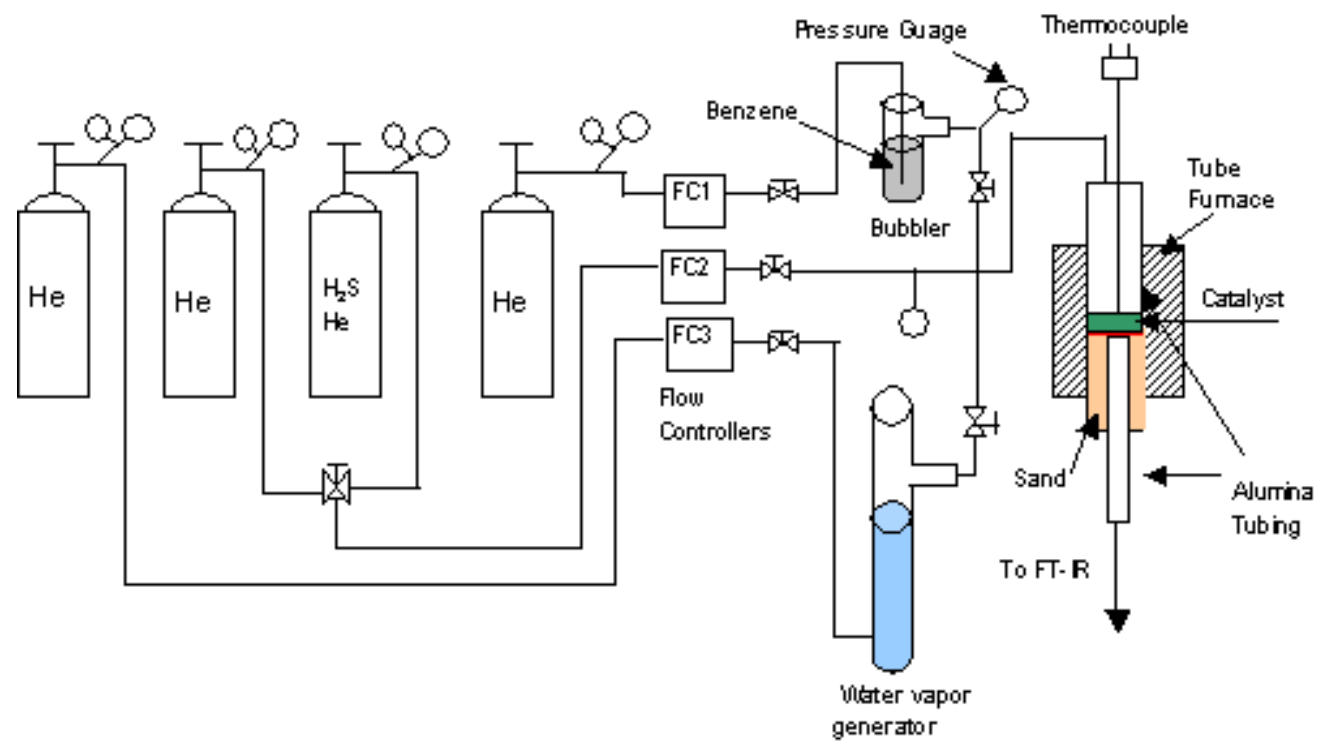

Figure 1. A schematic of the Reactor set-up 
Briefly, a $1 \frac{1}{2}$ inch diameter alumina tube served as the reactor tube that was placed inside a vertical tubular furnace. The feed gas system consisted of several gas streams that could be mixed in controlled flow rates to yield a desired feed composition. Benzene was introduced into the feed by sending helium through a benzene bubbler. Similarly, water (or steam) was generated by sending through a hot tube containing water at elevated temperature. All the feed lines leading to the reactor were heat-traced to prevent any condensation. Likewise, the reactor effluent lines were heat-traced for the same reasons. The reactor effluent was directly fed into an on-line FT-IR. A Bomen model MB-100 FTIR was used for real-time analysis of feed and product composition. The Table I below shows the typical reaction conditions used in this study.

Table I. Experimental Conditions for Catalytic Testing

\begin{tabular}{|l|c|c|}
\hline Variable & Normal Values & Operating Range \\
\hline Catalyst loading (gm) & 0.4 & $0.4-2$ \\
\hline Sand (gm) & 2 & $0-2$ \\
\hline Temperature $\left({ }^{\circ} \mathrm{C}\right)$ & 800 & $600-900$ \\
\hline Feed Flow Rate (ml/min) & 192 & $190-192$ \\
\hline Benzene concentration (\%) & 0.23 & $0.15-0.30$ \\
\hline Water concentration (\%) & 1.3 & $0.6-2.3$ \\
\hline Impurities when Tested & & $100-400$ \\
\hline H2S concentration (ppm) & 225 & $0.05-1$ \\
\hline Alkali loading (gm) & 0.2 & \\
\end{tabular}

A number of catalysts were tested- some prepared in the laboratory and some off-theshelf from manufacturers. These catalysts were pretreated (the exact pretreatment will be noted when appropriate) before being loaded into the reactor. Reaction-aged and fresh catalysts were stored in glass vials for XRD and SEM/EDS analyses. XRD studies were carried out using a Phillips PW1800 diffractometer. The SEM was a LEO 1530 model and EDS was an INCA Energy (model 7426) from Oxford Instruments. All other details are given elsewhere (12).

The model tar compound (benzene) is added by bubbling helium through a benzene container placed in a constant temperature water bath. A water vapor generator was used to feed water into the reactor. The reactor was operated at temperatures between $500^{\circ} \mathrm{C}$ 
and $800^{\circ} \mathrm{C}$. The reactor effluent stream was analyzed using on-line FTIR for $\mathrm{CO}, \mathrm{CO}_{2}$, $\mathrm{CH}_{4}$, and other hydrocarbons (including the reactant benzene), as well as sulfurcontaining compounds.

In initial runs, the catalyst weight was 0-2 gm, with an additional 2 gm of inert material (purified sand), except where noted: The feed stream consisted of $2400 \mathrm{ppm}$ benzene, while the water vapor concentration was adjusted to one and two times the stoichiometic need (1.44\% and $2.88 \%$ respectively) based on assuming total conversion of tar species to $\mathrm{CO}$ and $\mathrm{H}_{2}$. Balance of the feed stream was helium. In experiments where the effect of sulfur on catalyst activity was examined, 225-350 ppm $\mathrm{H}_{\mathrm{z}} \mathrm{S}$ was added to the feed stream; all else remained unchanged. Fine $\mathrm{Na}_{2} \mathrm{~S}$ and $\mathrm{Na}_{\mathrm{z}} \mathrm{CO}_{3}$ particles were added to the catalyst bed in order to study the effect of alkali salt on catalyst activity. Reactor-aged catalyst samples were stored under He in glass vials for further analyses using XRD, SEM etc.

\section{RESULTS SUMMARY}

\section{Task 1.1 Activity Measurements}

Table I lists the catalysts tested in Bench Scale Reactor studies. Group VIII transition metal catalysts (Pt, $\mathrm{Pd}, \mathrm{Rh}, \mathrm{Ru}, \mathrm{Ni}$ ) supported on $\mathrm{Al}_{2} \mathrm{O}_{3}, \mathrm{SiO}_{2}$, or $\mathrm{SiO}_{2}-\mathrm{A}_{2} \mathrm{O}_{3}$ were found to be active for benzene gasification using steam. Figure 2 shows the transient behavior for product gas concentrations for the $\mathrm{Pt} / \mathrm{A}_{2} \mathrm{O}_{3}$ catalyst at $700^{\circ} \mathrm{C}$. The major reaction products are $\mathrm{CO}$ and $\mathrm{CO}_{2}$, with small quantities of methane. Furthermore, the activity for $\mathrm{CO}$ formation decays slowly due to the build-up of carbonaceous species. Among all Group VIII transition metals, $\mathrm{Pt} / \mathrm{A}_{2} \mathrm{O}_{3}$ was the most active catalyst (at least on a per unit weight basis).

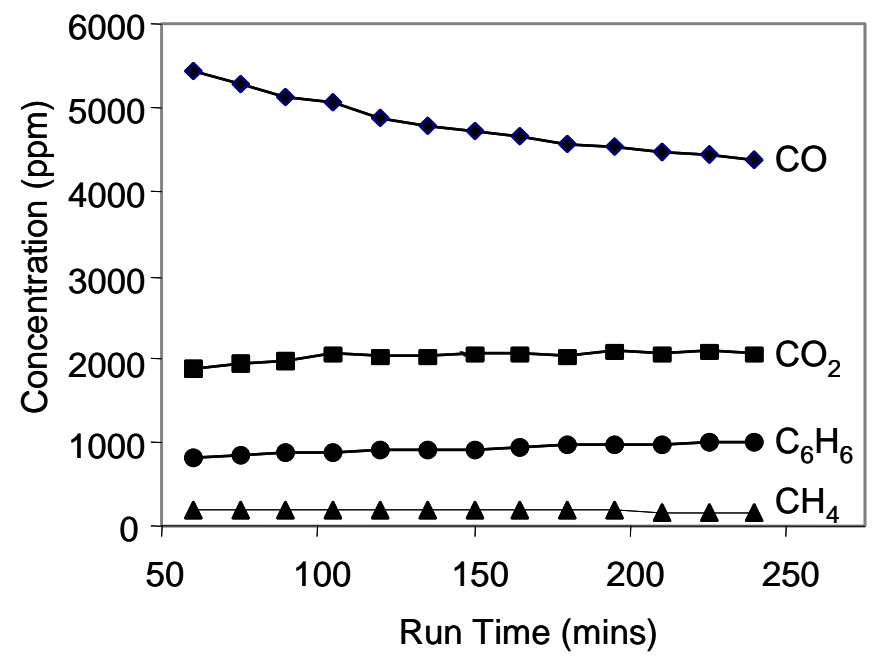

Figure 2. Product Gas Concentrations from a Catalyst Screening Test with $5 \% \mathrm{Pt} / \mathrm{Al}_{2} \mathrm{O}_{3}$ At $700{ }^{0} \mathrm{C}$. 
In contrast, mixed metal oxide catalysts showed significantly lower activity even at temperatures as high as $800^{\circ} \mathrm{C}$. The same was true of sulfided catalysts, e.g. CoS$\mathrm{MoS}_{2} / \mathrm{A}_{2} \mathrm{O}_{3}$ etc. The only exception appeared to be tungsten sulfide $\left(\mathrm{WS}_{2}\right)$ and nickel tungsten sulfide catalysts. At higher temperatures, much less $\mathrm{CO}_{2}$ is observed, and $\mathrm{CO}$ is the major reaction product. This is presumably due to the water gas shift reaction.

In order to allow a comparison between different catalysts, and to normalize against amount of catalysts used in the reactor, the catalyst activity was defined as reaction rate in moles $\left(\mathrm{CO}+\mathrm{CO}_{2}\right)$ per gm catalyst per minute. In the following pages, the rate results will be compared with and without $\mathrm{H}_{2} \mathrm{~S}$.

Table I. List of Catalysts Tested in Bench Scale Reactor

\section{Catalyst Description}

$5 \% \mathrm{Pt} / \mathrm{A}_{2} \mathrm{O}_{3}$

$5 \% \mathrm{Pd} / \mathrm{A}_{2} \mathrm{O}_{3}$

$5 \% \mathrm{Rh} / \mathrm{A}_{2} \mathrm{O}_{3}$

$5 \% \mathrm{Ru} / \mathrm{A}_{2} \mathrm{O}_{3}$

$64 \% \mathrm{Ni} / \mathrm{SiO}_{2}-\mathrm{Al}_{2} \mathrm{O}_{3}$

$24.4 \% \mathrm{Ni} / \mathrm{SiO}_{2}$

43\% CuO- $39 \% \mathrm{Cr}_{2} \mathrm{O}_{3} / \mathrm{Al}_{2} \mathrm{O}_{3}$

$3.5 \% \mathrm{CoO}+14 \% \mathrm{MoO} / \mathrm{A}_{2} \mathrm{O}_{3}$

$10 \% \mathrm{MoO}_{3} / \mathrm{A}_{2} \mathrm{O}_{3}$

$3 \% \mathrm{FeC}_{3} / \mathrm{SiO}_{2}-\mathrm{A}_{2} \mathrm{O}_{3}$

$4 \% \mathrm{CoO}-12 \% \mathrm{MoO}_{3} / \mathrm{A}_{2} \mathrm{O}_{3}$

Sulfided $\mathrm{CoO}-\mathrm{MoO}_{3} / \mathrm{A}_{2} \mathrm{O}_{3}$

Sulfided $\mathrm{NiO}-\mathrm{MoO}_{3} / \mathrm{A}_{2} \mathrm{O}_{3}$

Tungsten Sulfide $\left(\mathrm{WS}_{2}\right.$ )

Tungsten carbide (94\%), Cobolt (6\%)

Sulfided $\mathrm{WO}_{3} / \mathrm{A}_{2} \mathrm{O}_{3}$

$\mathrm{WS}_{2}-\mathrm{NiS}$

\section{$\underline{\text { Source }}$}

Aldrich

Alfa Aesar

Alfa Aesar

Alfa Aesar

Acros

Laboratory Prep.

Alfa Aesar

Alfa Aesar

Alfa Aesar

Alfa Aesar

Laboratory Prep.

Laboratory Prep.

Laboratory Prep.

Alfa Aesar

Alfa Aesar

Laboratory Prep.

Alfa Aesar 


\section{Task $1.2 \quad$ Deactivation Rates}

\section{Sulfur Deactivation}

Addition of 225-250 $\mathrm{ppm}_{2} \mathrm{~S}$ to the feed stream resulted in rapid loss of catalytic activity for most catalysts. Figure 3 shows the transient activity behavior for $5 \%$ $\mathrm{Pt} / \mathrm{A} 1_{2} \mathrm{O}_{3}$ Catalyst at $600^{\circ} \mathrm{C}$. For the initial 150 minutes, there was no sulfur present in the feed gas. The catalyst activity decayed slowly due to carbon deactivation and lost almost half of its initial activity due to carbon build-up. After 150 minutes, $225 \mathrm{ppm}_{2} \mathrm{~S}$ was introduced into the feed stream, the catalyst lost its activity very quickly.

Calculations showed that 30-40 min. would be needed to provide just enough $\mathrm{H}_{2} \mathrm{~S}$ to poison all surface sites. In the case of Group VIII transition metal catalysts, the catalyst activity continued to decay in the presence of $225 \mathrm{ppm} \mathrm{H}_{2} \mathrm{~S}$. In most cases, there was no visible activity left. Removal of sulfur from the feed stream after 320 minutes resulted in negligible recovery of the lost catalytic activity. XRD spectra of deactivated catalyst showed the formation of $\mathrm{PtS}_{2}$ bulk phase (Figure 4).

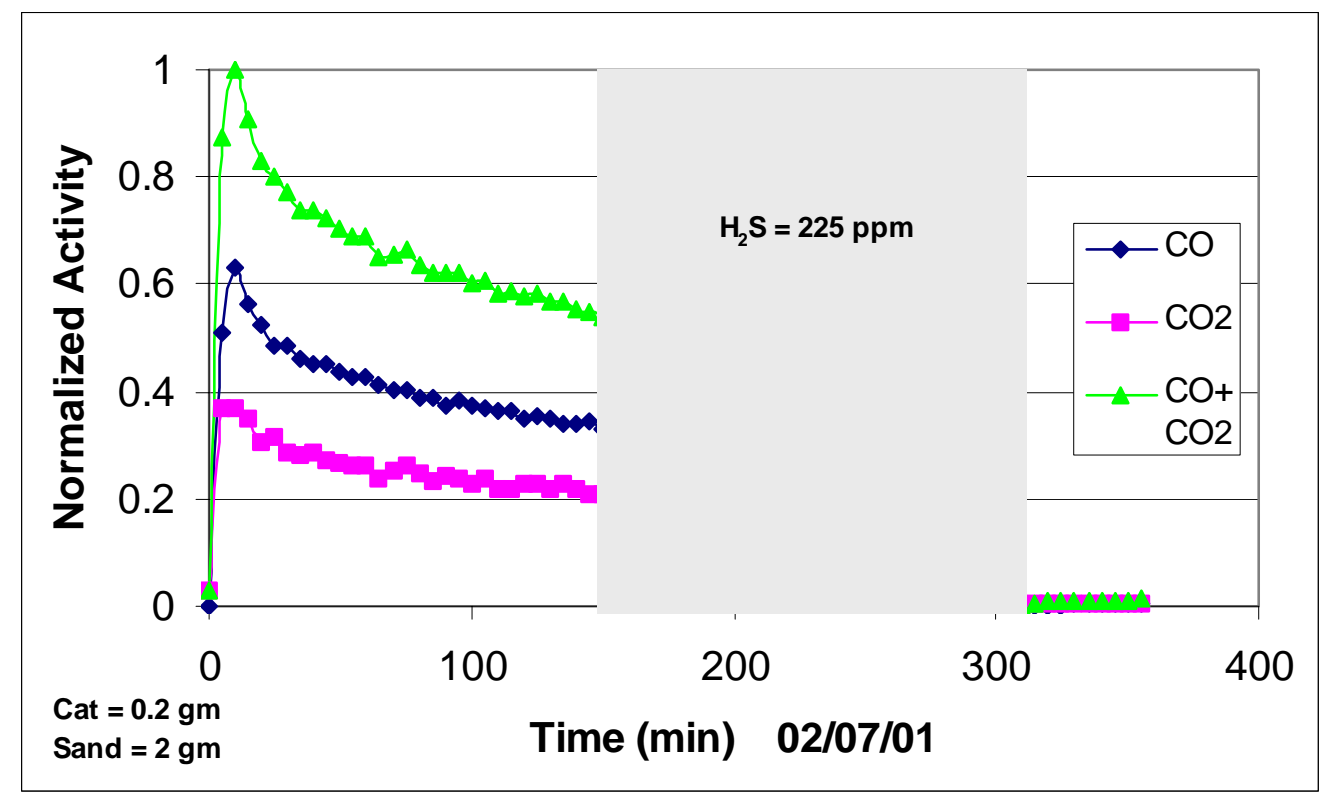

Figure 3. Effect of Sulfur Poisoning on the Benzene Reforming Activity of 5\% Pt/alumina Catalyst at $600{ }^{\circ} \mathrm{C}$

Efforts to regenerate poisoned catalyst using air/ $\mathrm{O}_{2}$ were unsuccessful. Group VIII transition metal catalysts that had been deactivated in the presence of $\mathrm{H}_{2} \mathrm{~S}$ were examined by x-ray diffraction. In all cases, formation of sulfide and/or sulfate phases was observed. Figure 5 shows typical XRD spectra of an aged Nickel catalyst that was exposed to reaction conditions at $800^{\circ} \mathrm{C}$ in the presence of $225 \mathrm{ppm}$ sulfur. Similar observations were made for nickel catalysts deactivated at other temperatures as well as for other Group VIII transition metals. 


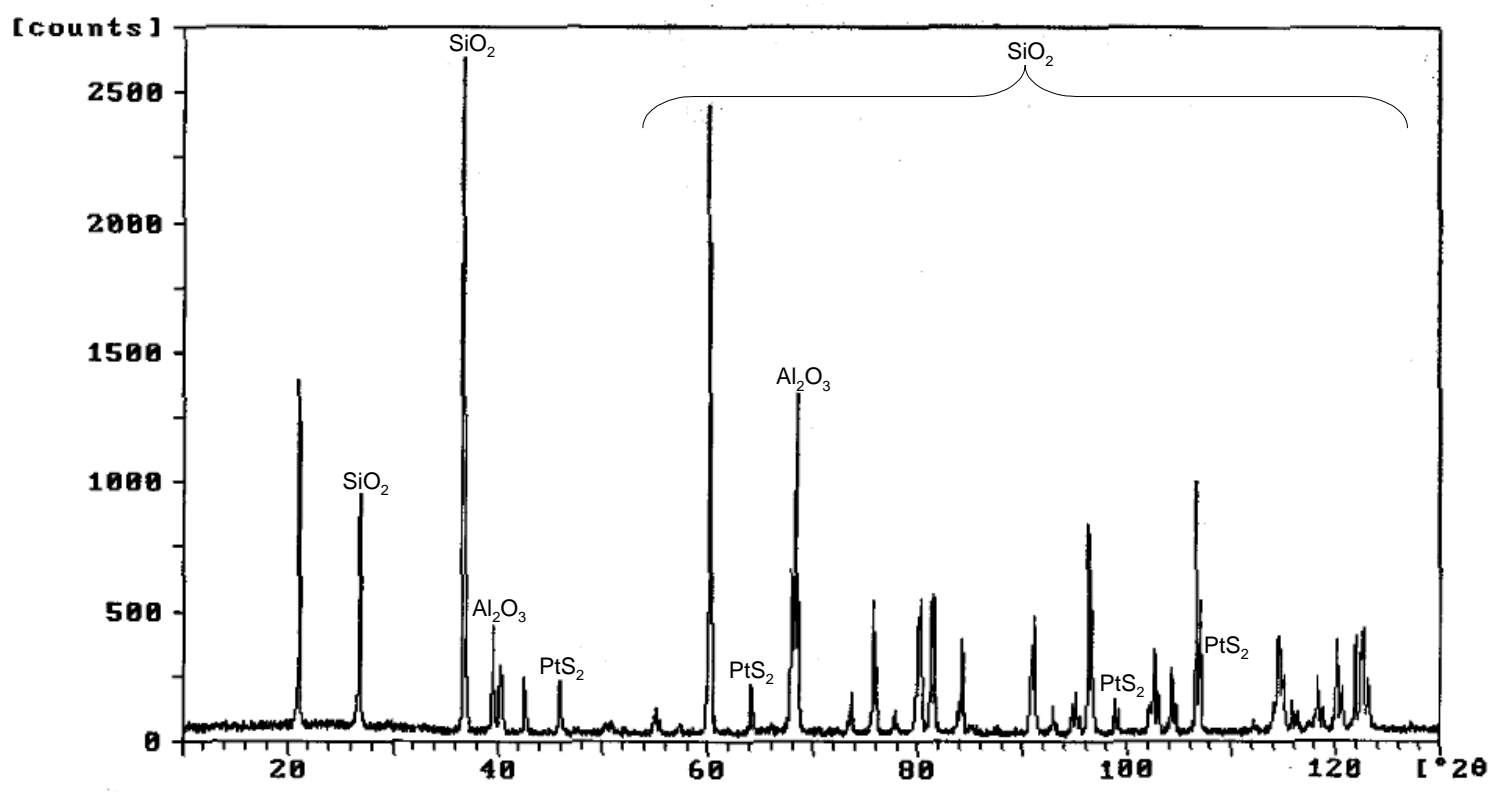

Figure 4. XRD Spectrum of sulfur-poisoned Platinum Catalyst

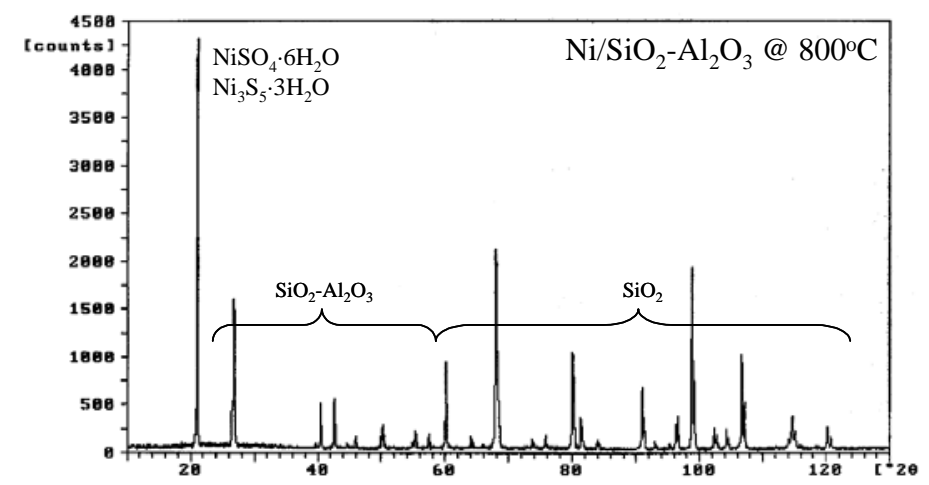

Figure 5. XRD Spectra of Sulfur-Poisoned Nickel Catalyst

A Ni/ $\mathrm{A}_{2} \mathrm{O}_{3}$ catalyst was calcined at $1000^{\circ} \mathrm{C}$ for 12 hours to yield nickel aluminate (spinel phase). However, this material showed no measurable catalytic activity for steam-benzene reaction. Same was true for nickel sulfide, nickel chromite, and tungsten carbide species.

The only exception in terms of sulfur-tolerance has been tungsten sulfide $\left(\mathrm{WS}_{2}\right)$, Co-Mo sulfides and Ni-W sulfide species. The activity at $600^{\circ} \mathrm{C}$ and $700^{\circ} \mathrm{C}$ is rather low. Hence the catalytic activity of these materials has been measured at $800^{\circ} \mathrm{C}$. There is a bit of caking involved with these materials, as evidenced by the difficulty in removing aged 
catalysts from the alumina reactor tube. This has affected the reproducibility of rate measurements. At least 20 different experiments have been performed with tungsten sulfide. Table II shows a summary of reaction rate (in the absence and in the presence of $\mathrm{H}_{2} \mathrm{~S}$ ). It is clear that the activity of $5 \% \mathrm{Pt} / \mathrm{A}_{2} \mathrm{O}_{3}$ goes to zero in the presence of 225-250 ppm $\mathrm{H}_{2} \mathrm{~S}$, whereas that of $\mathrm{WS}_{2}$ is largely unchanged in the presence of sulfur. This is the first material tested under mildly oxidizing conditions that shows sulfur tolerance. It is because of this unusual sulfur tolerance, in light of the behavior of other sulfided materials, that we have attempted to repeat the results multiple times; sulfur-tolerance has been confirmed. In contrast, cobalt-molybdenum sulfide catalysts (3.5\% CoO $-14 \%$ $\mathrm{MoO}_{3} /$ Alumina, Surface Area $=244 \mathrm{~m}^{2} / \mathrm{gm}$, Alfa Aesar) showed no poisoning effect of sulfur. Figure 6 shows the results from one such run.

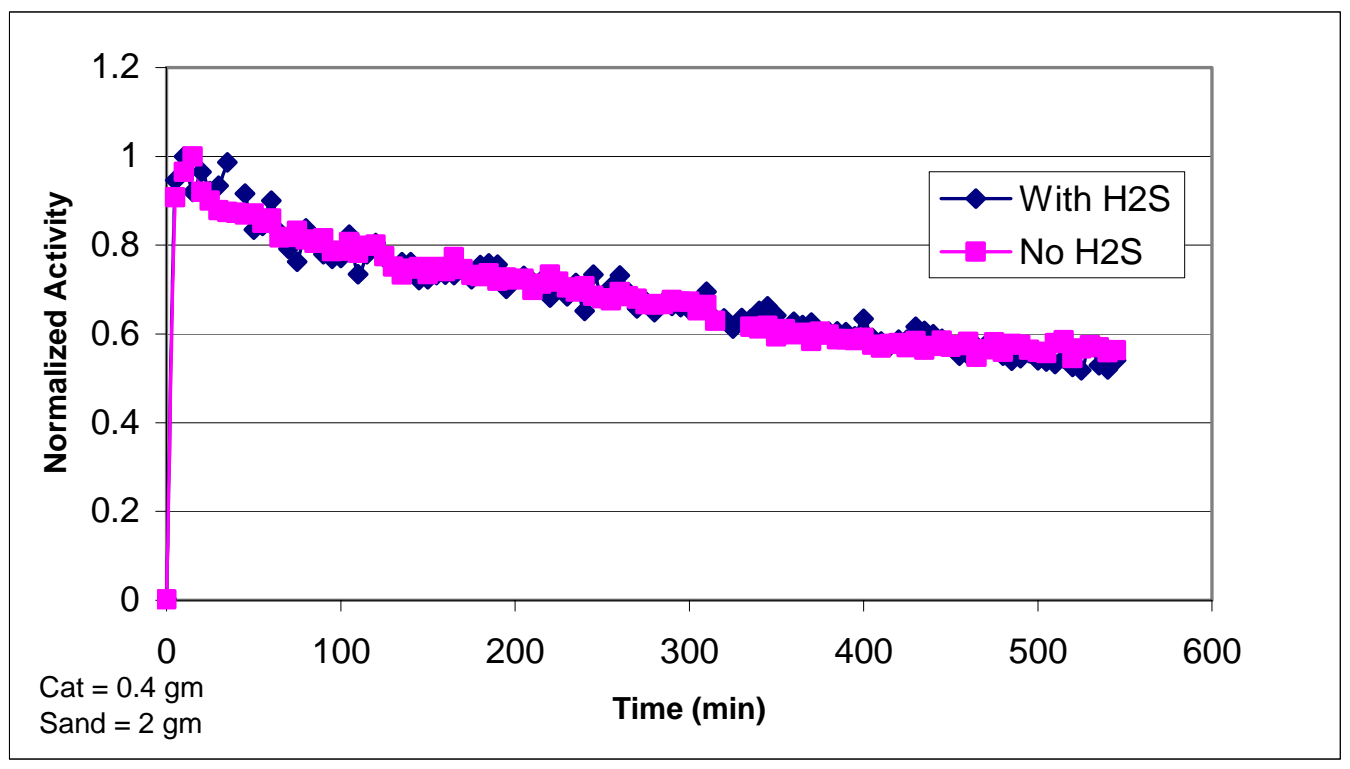

Figure 6. Effect of $225 \mathrm{ppm} \mathrm{H}_{2} \mathrm{~S}$ on normalized benzene reforming activity of sulfided Co-Mo catalyst at $800{ }^{\circ} \mathrm{C}$.

It is hard to distinguish between the two curves shown above (Figure 6). The slow deactivation is again due to the carbon build-up. The catalytic activity of the Co-Mo catalysts is lower than that of Pt catalysts (on a per gram basis) and we needed to use higher temperatures $\left(800{ }^{\circ} \mathrm{C}\right)$ to measure the activity. It is helpful to remember that poisoned Pt catalyst had little or no activity even at $800{ }^{\circ} \mathrm{C}$. Another item to note is that the intrinsic activity of Co-Mo remains unchanged in the presence of sulfur. It should also be noted that no attempt has been made yet to increase or optimize the activity of this sulfur-tolerant catalyst. These results were verified and confirmed in many reactor runs. 
Table II. Catalyst Deactivation by Sulfur

\begin{tabular}{|c|c|c|}
\hline \multirow{2}{*}{ CATALYST } & Reaction Rate & \multirow{2}{*}{$\frac{10^{-6} \text { moleo }\left(\mathrm{CO}+\mathrm{CO}_{2}\right) \text { gm cat-min }}{225-250 \mathrm{ppm} \mathrm{\textrm {H } _ { 2 } \mathrm { S }}}$} \\
\hline & No $\quad \mathrm{H}_{2} \mathrm{~S}$ & \\
\hline $5 \% \mathrm{Pt} / \mathrm{A}_{1} \mathrm{O}_{3}$ & 185 & \\
\hline & 154 & 0 \\
\hline $\mathrm{WS}_{2}$ (Alfa) & 3.48 & 3.43 \\
\hline & 1.40 & \\
\hline & 3.77 & \\
\hline & 3.67 & \\
\hline & 5.26 & 4.95 \\
\hline & 5.39 & 4.42 \\
\hline & 4.46 & 3.14 \\
\hline & 6.67 & \\
\hline
\end{tabular}

Blanks indicate where no sulfur poisoning experiment was carried out.

\subsection{Alkali Deactivation}

To check the effect of alkali deactivation, $\mathrm{Na}_{2} \mathrm{CO}_{3}$ and $\mathrm{Na}_{2} \mathrm{~S}$ were added to the catalyst bed (in separate runs). In the case of Group VIII transition metals, addition of $\mathrm{Na}_{2} \mathrm{CO}_{3}$ has little or no effect on the observed reaction rate (in the absence of $\mathrm{H}_{2} \mathrm{~S}$ ). With $\mathrm{H}_{2} \mathrm{~S}$ present in the feed, $\mathrm{Na}_{2} \mathrm{CO}_{3}$ appears to have negligible effect on the sulfur-tolerance (or a lack thereof) of Group VIII transition metals. There were weak indications that the addition of $\mathrm{Na}_{2} \mathrm{CO}_{3}$ might act as a scavenger for $\mathrm{H}_{2} \mathrm{~S}$ and thus delay the sulfur-poisoning effects. No significant effect of $\mathrm{Na}_{2} \mathrm{CO}_{3}$ addition was observed to warrant a more detailed investigation.

In contrast, when $\mathrm{Na}_{2} \mathrm{~S}$ was added to the catalyst bed, no activity was observed. Presumably, enough $\mathrm{H}_{2} \mathrm{~S}$ was generated during the initial start-up (heating phase) that the Group VIII transition metals were completely deactivated. Table III presents a summary of the role of alkali species in sulfur poisoning of Group VIII transition metals.

\begin{tabular}{|c|c|c|c|c|c|}
\hline \multicolumn{6}{|c|}{ TABLE III POISONING BY SULFUR COMPOUNDS } \\
\hline \multirow{2}{*}{ Catalyst } & \multirow{2}{*}{$\begin{array}{l}\text { Reactor } \\
\text { Temperature } \\
\left({ }^{\circ} \mathrm{C}\right)\end{array}$} & \multicolumn{4}{|c|}{ Time to $20 \%$ of initial activity } \\
\hline & & $\begin{array}{l}\text { w/o } \\
\text { (min) }\end{array}$ & $\mathrm{Na}_{2} \mathrm{CO}_{3}$ & $\begin{array}{l}\mathrm{Na}_{2} \mathrm{CO}_{3} \\
\text { (min) }\end{array}$ & $\begin{array}{l}\mathrm{Na}_{2} \mathrm{~S} \\
(\mathrm{~min})\end{array}$ \\
\hline $64 \% \mathrm{Ni}$ & 500 & 30 & & 30 & No activity \\
\hline $64 \% \mathrm{Ni}$ & 600 & 20 & & 25 & No activity \\
\hline $64 \% \mathrm{Ni}$ & 700 & 85 & & 80 & No activity \\
\hline $64 \% \mathrm{Ni}$ & 800 & 45 & & 45 & No activity \\
\hline $5 \% \mathrm{Pt}$ & 600 & 20 & & 25 & No activity \\
\hline $5 \% \mathrm{Ru}$ & 600 & 40 & & 40 & No activity \\
\hline
\end{tabular}


We also tested the effect of alkali metals (both $\mathrm{Na}_{2} \mathrm{CO}_{3}$ and $\mathrm{Na}_{2} \mathrm{~S}$ ) on the catalytic activity of tungsten sulfide $\left(\mathrm{WS}_{2}\right)$. In every case, we have found a total loss of catalytic activity. This result is rather surprising and unexpected, especially since $\mathrm{Na}_{2} \mathrm{CO}_{3}$ has no effect on Group VIII transition metals. XRD studies of aged $\mathrm{WS}_{2}$ catalyst identified the formation of inactive phases in the presence of alkali compounds. We examined the role of four different alkali salts: $\mathrm{Na}_{2} \mathrm{SO}_{4}, \mathrm{Na}_{2} \mathrm{~S}, \mathrm{Na}_{2} \mathrm{CO}_{3}$, and $\mathrm{NaCl}$. Interestingly, the effect of each salt was markedly different in terms of the transient behavior. Figure 7 shows the effect of $\mathrm{Na}_{2} \mathrm{SO}_{4}$. This run was begun with $225 \mathrm{ppm} \mathrm{H}_{2} \mathrm{~S}$ in the feed. The activity stabilizes after the first 100 minutes and there is very little deactivation after that. After 500 minutes of reactor operation with sulfur in the feed, $\mathrm{H}_{2} \mathrm{~S}$ was removed. Interestingly, removal of sulfur caused a loss of catalytic activity. After 1000 minutes of sulfur-free operation, the catalytic activity had been reduced by half. When sulfur was added back to the feed stream, there was a slow recovery in the catalytic activity. The slow loss and recovery of catalytic activity point to solid-state or bulk-phase transformations occurring in the sulfided Co-Mo catalysts.

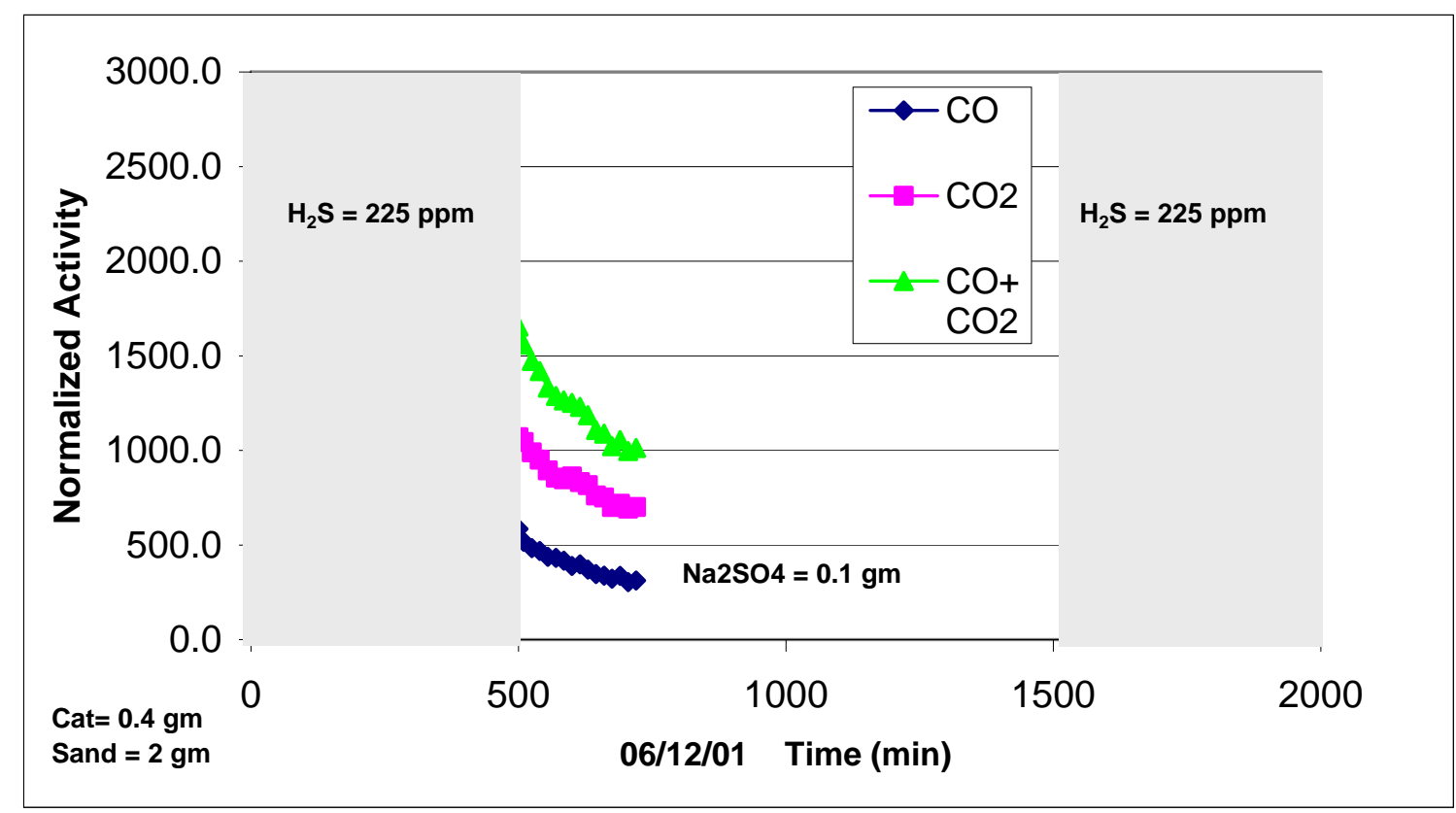

Figure 7. Benzene Reforming Activity of Sulfided Co-Mo $+\mathrm{Na}_{2} \mathrm{SO}_{4}$ at $800{ }^{\circ} \mathrm{C}$

The effect of $\mathrm{NaCl}$ on the transient activity behavior was even more complex and slow. As Figure 8 shows, the catalytic activity continued to increase over the first 800 minutes of reactor operation. When sulfur was removed from the feed stream, there was a gradual loss of catalytic activity over the next $600 \mathrm{~min}$. Figure 9 shows the XRD spectrum of unused, heated sulfided Co-Mo $+\mathrm{NaCl}$ catalyst. There is no trace of sodium molybdate or sodium aluminate, but there is affair amount of molybdenum sulfide $\left(\mathrm{MoS}_{2}\right)$. Figure 10 
shows the XRD spectrum of the same catalyst after being aged in the reactor. Now we see the presence of significant amounts of sodium molybdate. We generated similar information for other alkali compounds as well. It is possible to identify phases that are active for the stem reforming of benzene from the ones that are not active at all or have very low activity.

We have identified the following active phases for steam reforming of benzene:

$\mathrm{MoS}_{2}, \mathrm{MoO}_{2}$, and $\mathrm{Na}_{2}-\mathrm{O}-\mathrm{S}$

We also find that the following phases are inactive for the reaction:

$\mathrm{Na}_{2} \mathrm{MoO}_{4}$ and $\mathrm{NaAlO}_{2}$

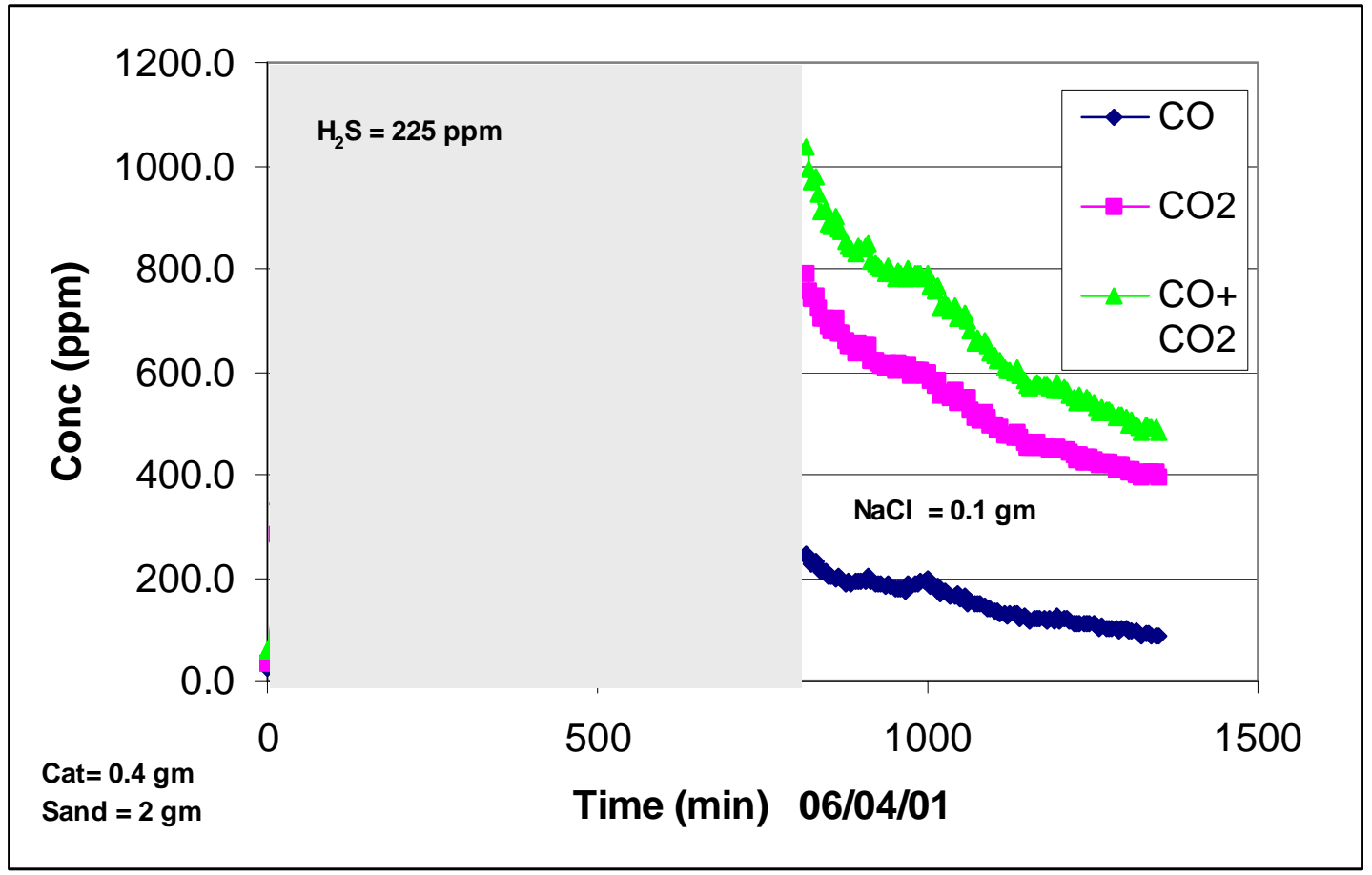

Figure 8. Benzene Steam Reforming Activity of Sulfided Co-Mo $+\mathrm{NaCl}$ at $800{ }^{\circ} \mathrm{C}$ 


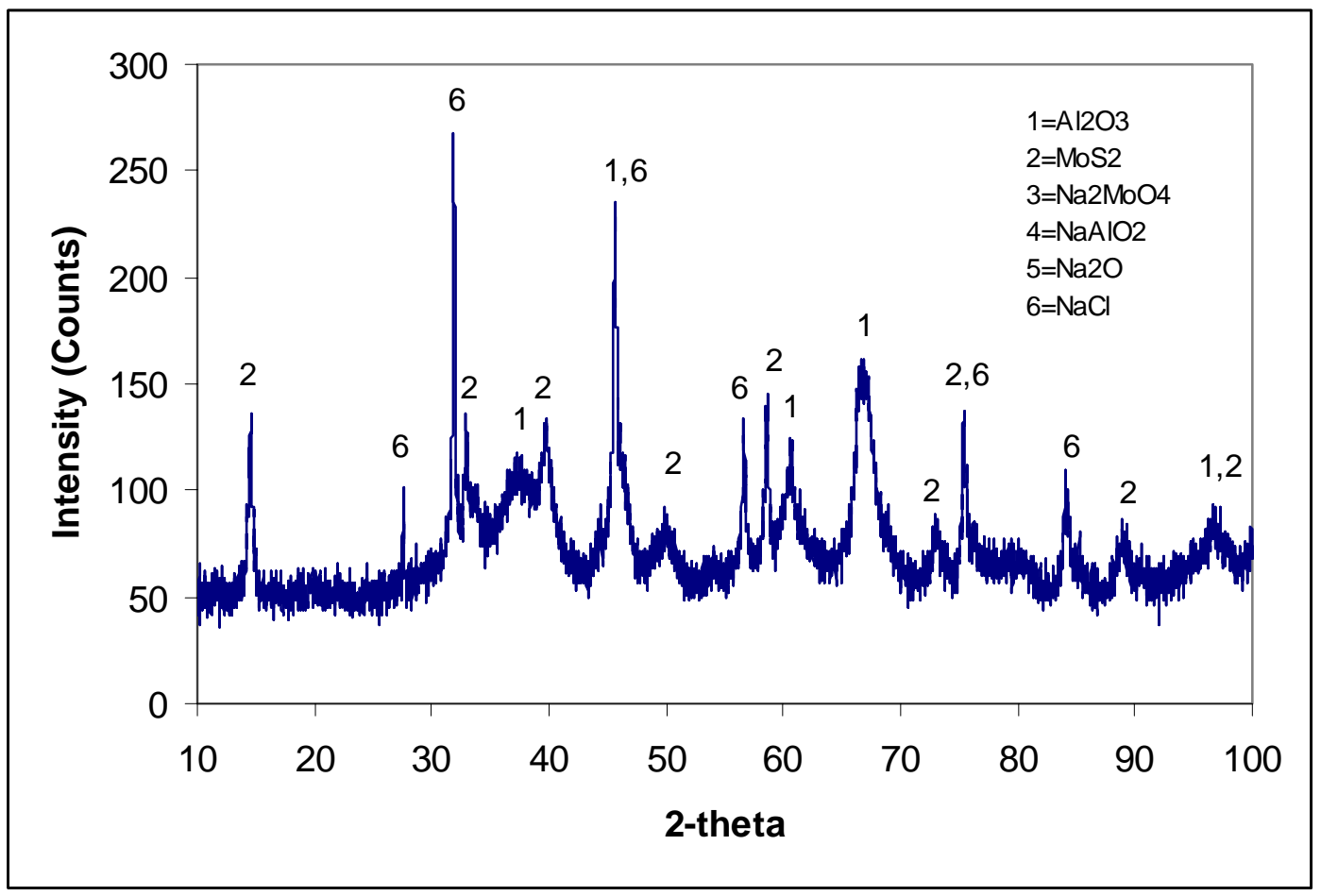

Figure 9. XRD Spectrum of Unused, Heated Sulfided Co-Mo + NaCl Catalyst

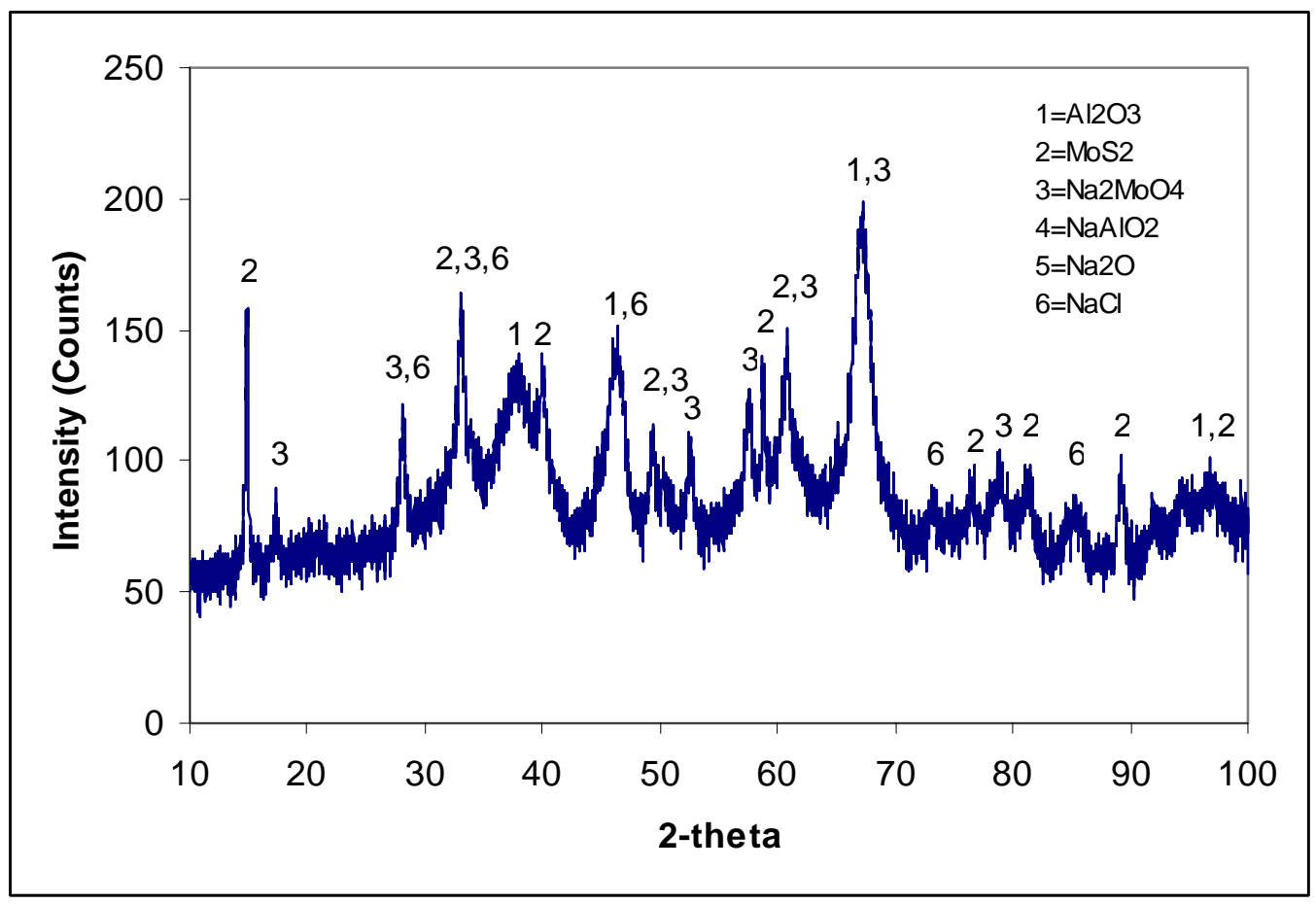

Figure 10. XRD Spectrum of Spent Sulfided Co-Mo + NaCl Catalyst 
In general, there are significant phase transformations occurring in the presence of alkali compounds. In the presence of alkali, it helps to have sulfur present in the feed to maintain the active phase. In the absence of sulfur, active phases of Co-Mo sulfides are degraded to inactive phases. Table IV presents a summary of the catalytic activity at various operating conditions.

Table IV. Steady State Activities of Sulfided Co-Mo for Various Process Conditions

\begin{tabular}{|c|c|c|c|}
\hline Catalyst & Reaction Rat & le $(\mathrm{CO}+\mathrm{CO} 2+$ & /gm-cat. minute \\
\hline Particle Size & No H2S & 225 ppm H2S & 350 ppm H2S \\
\hline \multicolumn{4}{|c|}{ Sulfided Co-Mo } \\
\hline PS: random & 45.9 & 40.1 & \\
\hline PS: $175-250 \mu \mathrm{m}$ & 29 & 30 & \\
\hline PS: $<175$, random & 31.4 & 30.1 & \\
\hline PS: $100-150 \mu \mathrm{m}$ & 34.4 & 31.9 & 27.0 \\
\hline \multicolumn{4}{|c|}{ With Alkali Metals } \\
\hline $0.2 \mathrm{gm} \mathrm{Na}_{2} \mathrm{CO}_{3}$ & 8.8 & 21.6 & 39.8 \\
\hline $0.1 \mathrm{gm} \mathrm{Na}_{2} \mathrm{SO}_{4}$ & 11.3 & 31.5 & \\
\hline $0.1 \mathrm{gm} \mathrm{NaCl}$ & 13.2 & 28.1 & 51.9 \\
\hline $0.2 \mathrm{gm} \mathrm{Na}_{2} \mathrm{~S}$ & 45.9 & 50.6 & 57.9 \\
\hline
\end{tabular}

\section{CONCLUSIONS}

Group VIII Transition metal catalysts are active for the steam reforming of benzene, but they deactivate rapidly in the presence of trace sulfur quantities. Sulfided phases of Group VIB-VIII show promise as sulfur-tolerant catalysts. Slow deactivation is caused by the carbon build-up, but deactivated catalysts can be regenerated by oxidation treatment. The presence of alkali species results in the formation of various phases and structures depending on the alkali species. These slow solid state transformations cause complex transient activity behavior. The presence of $225 \mathrm{ppm}_{2} \mathrm{~S}$ leads to the formation of sulfide and sulfate phases of Group VIII transition metals (e.g., Pt, Ni etc.), and this results in an almost complete and irreversible loss of catalytic activity for tar reforming. However, Group VIB-VIII sulfided catalysts maintain a stable catalytic activity in the presence of $\mathrm{H}_{2} \mathrm{~S}$ and show promise as potential catalytic candidates. 


\section{ACKNOWLEDGEMENT}

We wish to acknowledge the financial support of this work by a Department of Energy grant (No. DE-FC07-00ID13875).

\section{REFERENCES}

1. Sricharoenchaikul, V., Frederick, Jr. W. J. and Agrawal, P. K., "Black Liquor Gasification Characteristics. 1. Formation and Conversion of Carbon-Containing Product Gases”, Ind. Eng. Chem. Res. 41, 5640 (2002).

2. Sricharoenchaikul, V., Frederick, Jr. W. J. and Agrawal, P. K., “Black Liquor Gasification Characteristics. 2. Measurements of Condensable Organic Matter (Tar) at Rapid Heating Conditions”, Ind. Eng. Chem. Res. 41, 5650 (2002).

3. Kinoshita, C. M., Wang, Y. and Zhou, J., "Effect of Reformer Conditions on Catalytic Reforming of Biomass Gasification Tars”, Ind. \& Eng. Chem Res., 34, 2949 (1995).

4. Aznar, M.P., Caballero, M. A., and Gil, J., "Commercial Steam Reforming Catalysts to Improve Biomass Gasification with Steam-Oxygen Mixtures”, Ind. \& Eng. Chem. Res., 37, 2668 (1998).

5. Narvaez, I., Corella, J., and Orio, A., "Fresh Tar (from a biomass Gasifier) Elimination Over a Commercial Steam-Reforming Catalyst. Kinetics and Effect of Different Variables of Operation”, Ind. \& Eng. Chem. Res., 36, 317 (1997).

6. Simell, P.A., Hakala, N. A. K., and Haario, H. E., “Catalytic Decomposition of Gasification Gas Tar with Benzene as Model Compound”, Ind. \& Eng. Chem.Res., 36, 42 (1997).

7. Aznar, M. P., Corella, J., Delgaso, J. and Lahoz, J., “Improved Steam Gasification Of Lignocellulosic Residues in a Fluidized Bed with Commercial SteamReforming Catalysts”, Ind. \& Eng. Chem. Res., 32, 1 (1993).

8. Alden, H., Espenas, B. G., and Runsfelt, E., "Conversion of Tar in Pyrolysis Gas From Wood Using a Fixed Dolomite Bed”, Res. Thermochem. Biomass Conversion, 987-1001 (1988).

9. Gates, B. C., Katzer, J. R. and Schuit, G. C. A., "Chemistry of Catalytic Processes”, McGraw-Hill, New York, 1979, pp. 184, 390-425.

10. “Catalyst Deactivation in Studies in Surface Science and Catalysis”, eds. B. Delmon and G. Froment, Elsevier, New York, 1980. 
11. Hepola, J. and Simell, P., "sulfur poisoning of Nickel-Based Hot Gas Cleaning Cata;ysts in Synthetic Gasification Gas”, Applied Catalysis, B. (14), 287 (1997).

12. Amlani, A. D., "Sulfur Tolerance of Catalysts For Tar Destruction in Black Liquor and Biomass Gasification”, Georgia Institute of Technology, MChE Thesis, 2002. 